http://dx.doi.org/10.1590/1678-4162-7934

Arq. Bras. Med. Vet. Zootec., v.67, n.6, p.1684-1692, 2015

\title{
Consumo, desempenho e análise econômica da alimentação de cordeiros terminados em confinamento com o uso de dietas de alto grão
}

\author{
[Consumption, performance and economic analysis of the feeding of lambs finished in \\ feedlot as the use of high-grain diets] \\ G.M.C. Bernardes ${ }^{1}$, S. Carvalho ${ }^{2 *}$, C.C. Pires ${ }^{2}$, J.H. Motta ${ }^{3}$, W.S. Teixeira ${ }^{3}$, L.I. Borges ${ }^{3}$, \\ M. Fleig ${ }^{3}$, V.M. Pilecco ${ }^{1}$, E.T. Farinha ${ }^{3}$, R.S. Venturini ${ }^{1}$ \\ ${ }^{1}$ Aluno de pós-graduação - Universidade Federal de Santa Maria - Santa Maria, RS \\ ${ }^{2}$ Universidade Federal de Santa Maria - Santa Maria, RS \\ ${ }^{3}$ Aluno de graduação - Universidade Federal de Santa Maria - Santa Maria, RS
}

\begin{abstract}
RESUMO
O presente experimento, conduzido no Laboratório de Ovinocultura da Universidade Federal de Santa Maria, teve como objetivo avaliar o efeito do uso de diferentes dietas de alto grão sobre o consumo de nutrientes e o desempenho de cordeiros terminados em confinamento, bem como realizar uma análise econômica da alimentação utilizada para terminação dos animais. Foram utilizados 32 cordeiros machos, castrados, da raça Texel, nascidos de parto simples e desmamados com aproximadamente 50 dias de idade. Os tratamentos foram constituídos por diferentes tipos de grãos, não processados, sendo: grão de milho, grão de aveia branca, grão de aveia preta ou grão de arroz com casca. Os animais foram abatidos quando atingiram o peso vivo de abate pré-estabelecido de $32 \mathrm{~kg}$, que corresponde a $60 \%$ do peso adulto de suas mães. Cordeiros alimentados com dietas de alto grão de milho apresentam maiores consumos de matéria seca, matéria orgânica, proteína bruta, carboidratos totais e de nutrientes digestíveis totais, menor consumo de fibra em detergente neutro, melhor escore de condição corporal, ganho de peso e conversão alimentar, o que leva à redução do número de dias no confinamento necessários para atingir o peso de abate. Além disso, cordeiros terminados com o uso de dieta de alto grão à base de grão de milho proporcionam melhor resultado econômico quando comparados com cordeiros terminados com as demais dietas de alto grão utilizadas neste experimento. $\mathrm{O}$ uso de dietas de alto grão de milho, aveia branca, aveia preta ou arroz com casca para terminação de cordeiros em sistema de confinamento é uma alternativa viável do ponto de vista produtivo. Porém, o uso de grão de milho proporciona melhores resultados produtivos e econômicos.
\end{abstract}

Palavras-chave: conversão alimentar, ganho de peso, ovinos, Texel

\begin{abstract}
This experiment was conducted at the Laboratory of Sheep, Federal University of Santa Maria, and aimed to evaluate the effect of using different high-grain diets on nutrient intake and performance of lambs in a feedlot, as well as conduct an economic analysis of feeding used for termination of the animals. A total of 32 Texel breed castrated male lambs, born from a simple birth and weaned at approximately 50 days of age were used. The treatments consisted of different types of grains, unprocessed, as follows: corn grain, white oat grain, black oat grain or grain of rice in the husk. The animals were slaughtered when they reached a pre-established body weight of $32 \mathrm{~kg}$ for slaughter, which corresponds to $60 \%$ of the mature weight of their mothers. Lambs fed diets with high corn grain have higher intakes of dry matter, organic matter, crude protein, total digestible nutrients and total carbohydrate, lower consumption of neutral detergent fiber and better body condition score, weight gain and feed conversion, which leads to reduction in the number of days in confinement needed to reach
\end{abstract}

Recebido em 24 de agosto de 2014

Aceito em 7 de julho de 2015

*Autor para correspondência (corresponding author)

E-mail: scarvalhoufsm@hotmail.com 
slaughter weight. In addition, lambs using high-grain diet based grain corn provide better economic results when compared with lambs with other high-grain diets used in this experiment. The use of diets high in grain corn, white oat grain, black oat grain or grain of rice in the husk for finishing lambs in feedlot is a viable alternative from a productive point of view. However, the use of corn grain provides better performance and economic results.

Keywords: feed conversion, weight gain, sheep, Texel

\section{INTRODUÇÃO}

A produção de carne ovina no Brasil apresenta um enorme potencial de expansão, sustentada pela alta demanda do mercado doméstico e pela limitada oferta no mercado internacional. Dessa forma, estudos vêm sendo realizados na busca por novos sistemas de produção, destacando-se, nesse caso, a introdução da desmama precoce, com terminação dos cordeiros em sistema de confinamento total.

Devido ao crescente desenvolvimento das áreas de agricultura, torna-se inevitável a intensificação das áreas de produção animal, onde o confinamento, principalmente de cordeiros destinados ao abate, vem sendo cada vez mais adotado. Sendo assim, a ovinocultura, como forma de seguir se aperfeiçoando e se tornando mais competitiva economicamente no mercado, utiliza o confinamento como alternativa de produção (Carvalho et al., 1999).

Contudo, a opção pela utilização do sistema de terminação de cordeiros em confinamento pressupõe investimentos adicionais, sobretudo no que diz respeito às instalações e à alimentação. Para que esses investimentos tenham retorno na forma de lucro para os produtores, estudos estão sendo realizados para tornar esse sistema de produção mais eficiente.

Diante disso, a terminação de cordeiros em confinamento, com o uso de dietas de alto grão, vem sendo estudada com o objetivo de diminuir o tempo de permanência dos ovinos em confinamento para atingir o peso de abate no qual os animais apresentem um adequado grau de acabamento da carcaça para ser comercializada (Carvalho et al., 2007).

Dietas com altos teores de concentrados energéticos apresentam vantagens em comparação às dietas ricas em volumosos, pois são de fácil armazenagem e manejo para fornecimento aos animais, proporcionam rápido acabamento de carcaça e ganho de peso elevado em animais confinados (Vechiato e Ortolani, 2008). Além disso, ingredientes concentrados dificilmente apresentam variações em sua composição nutricional, pois o seu processamento de secagem ocorre em nível industrial.

Outro fator a ser destacado é que, segundo Paniago (2014), sistemas de produção que são projetados para utilização de dietas com alta participação de volumosos exigem áreas próprias para produção desse ingrediente, onde a necessidade da produção do volumoso na propriedade está ligada a maior investimento em maquinário e a menor área disponível para produção a pasto quando comparado com sistemas que utilizam rações de alto grão. Além disso, com a evolução crescente da agricultura e a diminuição da área destinada à criação de animais, essa proposta de se intensificar cada vez mais a criação de ovinos torna-se relevante, podendo-se utilizar grãos impróprios para o consumo humano ou que, por motivos de mercado, se encontrem com um preço favorável à sua utilização, como é o caso dos grãos de milho, aveia branca, aveia preta e arroz com casca.

Sendo assim, este trabalho foi conduzido com o objetivo de avaliar o consumo e o desempenho de cordeiros terminados em confinamento e submetidos a dietas de alto grão, bem como realizar uma análise econômica da alimentação ofertada aos animais.

\section{MATERIAL E MÉTODOS}

O trabalho foi conduzido no Laboratório de Ovinocultura do Departamento de Zootecnia da Universidade Federal de Santa Maria, Santa Maria, RS, no período de agosto a novembro de 2012. Foram utilizados 32 cordeiros machos, castrados, da raça Texel, nascidos de parto simples e desmamados com aproximadamente 50 dias de idade. Os cordeiros eram oriundos de um 


\section{Bernardes et al.}

rebanho selecionado, atendendo às características raciais da raça a ser trabalhada, em que as ovelhas apresentavam peso vivo médio de $53,5 \mathrm{~kg}$.

Os animais foram confinados em baias individuais, totalmente cobertas, com piso ripado, aproximadamente $1,0 \mathrm{~m}$ acima do solo, com dimensão de $2 \mathrm{~m}^{2}$ por animal, e providas de comedouros e bebedouros individuais. Os tratamentos foram constituídos por diferentes tipos de grãos, não processados, sendo: grão de milho (Zea mays), grão de aveia branca (Avena sativa), grão de aveia preta (Avena stringosa) ou grão de arroz com casca (Oryza sativa L.) A dieta foi constituída pelo grão inteiro utilizado no tratamento, $15 \%$ de um núcleo concentrado comercial, farelo de soja e calcário calcítico. As dietas foram formuladas para serem isoproteicas e atender às exigências da categoria utilizada, segundo o NRC (2007). Na Tabela 1, é apresentada a proporção dos ingredientes e a composição bromatológica das dietas experimentais.

A ração foi ofertada aos animais ad libitum, duas vezes ao dia, sendo os horários de arraçoamento às 8 e 17 horas. A quantidade ofertada foi ajustada em função da sobra observada diariamente, sendo que esta deveria ser $10 \%$ da quantidade oferecida no dia anterior, de modo a garantir o consumo voluntário máximo dos animais. Os animais possuíam acesso, ad libitum, a sal mineral, em recipientes individuais, próprios para esse fim. A composição química do sal mineral utilizado era: (Cálcio: 134g; Fósforo: 60g; Magnésio: 10g; Sódio: 110g; Enxofre: 12g; Cobalto: 150mg; Iodo: $60 \mathrm{mg}$; Ferro: $2.500 \mathrm{mg}$; Manganês: $4.500 \mathrm{mg}$; Selênio: 30mg; Zinco: $6.000 \mathrm{mg}$; Flúor (máx.): 570mg; Palatabilizante: $180 \mathrm{~g})$.

Tabela 1. Proporção dos ingredientes (\%MS) e composição bromatológica das dietas experimentais

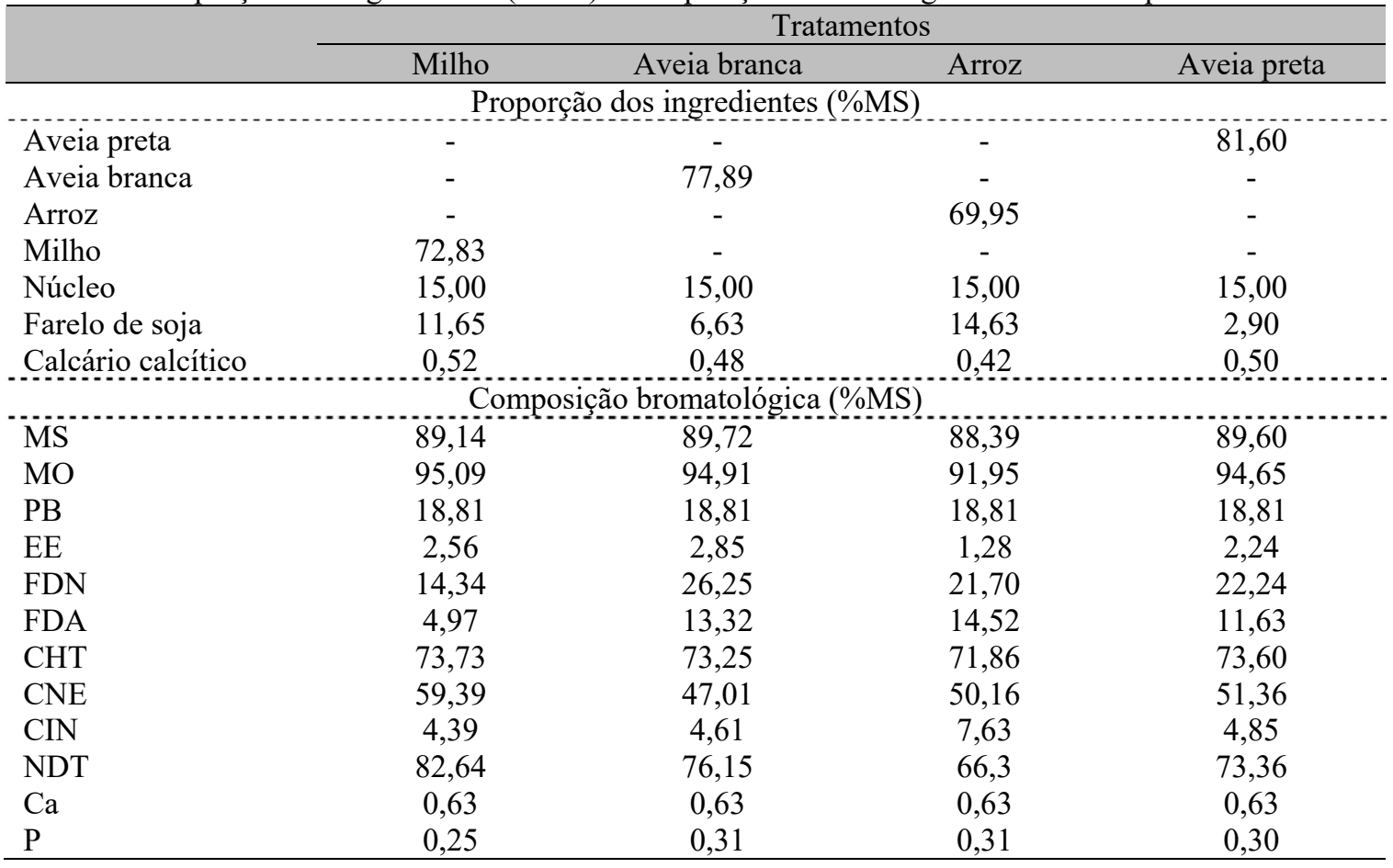

O período experimental foi precedido de um período de 10 dias para adaptação dos animais ao alimento, às condições de instalações e ao manejo. Nessa fase, para aprendizado de consumo de alimento sólido no comedouro por parte dos animais, foi fornecido feno de alfafa triturado como parte da alimentação e o grão utilizado no tratamento, em uma proporção inicial de volumoso:concentrado de 45:55\%. Posteriormente, até o início do período experimental, a cada dois dias, o feno de alfafa era substituído gradativamente em uma 
proporção de $15 \%$ pelo grão de cereal a ser utilizado, conforme o tratamento no qual o cordeiro se encontrava. O ensaio de alimentação iniciou após o período de adaptação, estendendose até o momento em que cada cordeiro atingia o peso de abate pré-estabelecido de $32 \mathrm{~kg}$, que corresponde a $60 \%$ do peso adulto de suas mães, segundo recomendação de Butterfield (1988).

Os cordeiros foram pesados no início e final da fase experimental, após jejum de sólidos de 14 horas, sendo que, para um melhor acompanhamento do desempenho dos animais, foram realizadas pesagens intermediárias a cada 14 dias.

Foram coletadas, a cada dois dias, amostras das sobras $(10 \%$ do peso total) e dos alimentos oferecidos, sendo feitas amostras compostas a cada 21 dias. Estas foram acondicionadas em sacos plásticos identificados e armazenadas em freezer a $-10^{\circ} \mathrm{C}$, para posteriores análises laboratoriais. As amostras dos alimentos fornecidos e as sobras foram pré-secas em estufa ventilada a $55^{\circ} \mathrm{C}$ por aproximadamente 72 horas e, posteriormente, moídas em moinho tipo "Willey" com peneira de $1 \mathrm{~mm}$. A determinação dos teores de matéria seca (MS) foi realizada por secagem em estufa a $105^{\circ} \mathrm{C}$ durante 24 horas, e de cinzas por incineração em mufla a $550^{\circ} \mathrm{C}$ por duas horas (Silva e Queiroz, 2002). A fibra insolúvel em detergente neutro (FDN) e fibra insolúvel em detergente ácido (FDA) foram determinadas segundo metodologia descrita por Senger et al. (2008). O teor de nitrogênio total (N) foi determinado pelo método Kjeldahl (AOAC, 1995), modificado segundo Kozloski et al. (2003). Para conversão dos valores de $\mathrm{N}$ em proteína bruta $(\mathrm{PB})$, foi utilizado o fator de correção de 6,25. A determinação dos teores de extrato etéreo (EE) foi realizada em sistema de refluxo de éter (Soxtherm, Gerhardt, Alemanha) a $180^{\circ} \mathrm{C}$ durante duas horas. Os teores de carboidratos totais (CHT) foram calculados segundo Sniffen et al. (1992), em que CHT (\%) $=100-(\% \mathrm{~PB}+\% \mathrm{EE}+\% \mathrm{CIN})$, e os teores de carboidratos não estruturais $(\mathrm{CNE})$, pela diferença de CHT - FDN.

Ao atingirem o peso vivo de abate, os cordeiros eram pesados sem jejum para obtenção do peso vivo de fazenda (PVFAZ) e, em seguida, eram submetidos ao jejum de 14 horas. Após esse período, os animais eram novamente pesados, sendo obtido o peso vivo ao abate (PVA). Pela diferença entre o PVFAZ e o PVA obteve-se o índice de quebra ao jejum (QJ). Após a pesagem final, foram avaliados in vivo, de forma subjetiva, a conformação (escala de 1 a 5, em que $1=$ muito pobre e $5=$ excelente) e o escore de condição corporal (escala de 1 a 5 , em que $1=$ muito magro e $5=$ obeso), conforme procedimentos descritos por Osório et al. (1998).

Realizou-se a análise econômica da alimentação utilizada no experimento, sendo que, para isso, foram obtidos os valores médios de mercado praticados no momento e na região do estudo para os ingredientes das rações e peso vivo dos cordeiros. De posse do custo de cada ração e do seu consumo, foi calculado o resultado econômico proporcionado por ração. Consideraram-se os seguintes valores: milho $\mathrm{R} \$$ $0,38 / \mathrm{kg}$, aveia branca $\mathrm{R} \$ 0,45 / \mathrm{kg}$, arroz com casca $\mathrm{R} \$ 0,59 / \mathrm{kg}$, aveia preta $\mathrm{R} \$ 0,55 / \mathrm{kg}$, núcleo $\mathrm{R} \$ 1,20 / \mathrm{kg}$, farelo de soja $\mathrm{R} \$ 0,90 / \mathrm{kg}$ e calcário calcítico R\$ 0,30/kg. Já no momento da comercialização dos animais o preço praticado para os cordeiros era de $\mathrm{R} \$ 4,20 / \mathrm{kg}$ de peso vivo (Agrolink, 2014).

O delineamento experimental utilizado foi inteiramente casualizado, no qual, para avaliação das quatro dietas experimentais, foram utilizadas oito repetições. Após a coleta dos dados, os resultados foram submetidos à análise de variância e as médias comparadas pelo teste Tukey, adotando-se o nível de significância de $5 \%$. As análises foram realizadas utilizando-se o pacote estatístico SAS (2004). O presente trabalho faz parte do projeto aprovado pelo Comitê de Ética no Uso de Animais do Centro de Ciências Rurais da Universidade Federal de Santa Maria (CEUA-UFSM), protocolo: 006.

\section{RESULTADOS E DISCUSSÃO}

Os consumos de matéria seca (CMS) e de matéria orgânica (CMO), nas diferentes formas em que foram expressos, apresentaram diferença significativa entre os tratamentos, sendo que os cordeiros do tratamento do grão de milho foram os que apresentaram os maiores consumos (Tab. 2). A menor proporção de FDN e de FDA e maior de $\mathrm{CNE}$ presentes na dieta à base de grão de milho, em comparação com as dietas à base de aveia branca, aveia preta ou arroz com casca, pode explicar o resultado obtido. Além disso, 


\section{Bernardes et al.}

pode-se inferir que o núcleo proteico e tamponante utilizados foram efetivos para manutenção do $\mathrm{pH}$ ruminal dos cordeiros com alta proporção de $\mathrm{CNE}$, evitando a ocorrência de possíveis distúrbios metabólicos que viessem a influenciar negativamente sobre esses consumos.

Por outro lado, os menores consumos de MS e de MO foram observados para o tratamento à base de grão de arroz, porém não diferindo em relação ao consumo dos cordeiros do tratamento de grão de aveia branca. $\mathrm{O}$ maior conteúdo de lignina e de sílica presente na casca do arroz ocasiona redução na digestibilidade e na taxa de passagem do alimento pelo trato gastrintestinal dos animais, o que pode ajudar a explicar o resultado obtido. Além disso, uma possível redução da palatabilidade do alimento e o efeito abrasivo que a casca de arroz normalmente proporciona ao trato gastrintestinal podem ter levado à redução do consumo dos cordeiros.

O consumo médio de matéria seca, expresso em $\% \mathrm{PV}$, dos cordeiros do tratamento de grão de milho foi semelhante ao verificado por Borges et al. (2011), que testaram a substituição de grão de milho inteiro por grão de aveia preta no confinamento de cordeiros, e obtiveram no tratamento sem substituição, no qual havia uma proporção de $84,75 \%$ de grão de milho, um consumo de matéria seca médio de $3,21 \%$ do PV. $\mathrm{O}$ resultado obtido no presente estudo possibilita afirmar que ocorreu uma maior capacidade de ingestão diária de grão de milho em relação aos demais grãos testados, principalmente devido à sua maior taxa de passagem e desaparecimento no trato gastrointestinal determinada pela maior proporção de CNE presente nesse grão.

Quanto ao consumo de fibra insolúvel em detergente neutro (CFDN), observa-se um valor médio de $0,56 \%$ (Tab. 2), o que está bem abaixo do valor preconizado por Mertens (1992) para que ocorra limitação física do consumo em ruminantes, que é de $1,2 \%$ do peso vivo. Portanto, pode-se inferir que, no presente estudo, o consumo tenha sido basicamente controlado pela regulação fisiológica dos animais, de acordo com o atendimento das suas exigências de energia.

O consumo de proteína bruta (CPB) dos cordeiros do tratamento de grão de milho também foi superior em relação aos dos demais tratamentos, sendo essa uma consequência do maior CMS observado, uma vez que as dietas foram formuladas para serem isoproteicas. O valor médio verificado para $\mathrm{CPB}$, que foi de $139 \mathrm{~g} /$ dia, está de acordo com o NRC (2007), que preconiza exatamente esse valor para cordeiros com $30 \mathrm{~kg}$ de PV e ganho de peso médio diário de $250 \mathrm{~g}$.

Quanto ao consumo de NDT, também se verifica superioridade nos cordeiros do tratamento do grão de milho (Tab. 2), sendo uma consequência do maior consumo de matéria seca e da maior concentração de energia na dieta dos animais submetidos a esse tratamento (Tab. 1). O NRC (2007) preconiza um consumo diário de NDT de $500 \mathrm{~g} /$ dia, para cordeiros com $30 \mathrm{~kg}$ de PV e ganho de peso médio diário de $250 \mathrm{~g}$. Verifica-se que o valor obtido para consumo de NDT dos cordeiros do tratamento do grão de milho foi de $731 \mathrm{~g}$ por dia e para os cordeiros do tratamento de grão de arroz foi de 398g; portanto, acima e abaixo, respectivamente, do valor preconizado e, dessa forma, exercendo influência sobre $\mathrm{o}$ desempenho animal.

O consumo de extrato etéreo (CEE) dos cordeiros dos tratamentos de milho e aveia branca foi superior ao dos cordeiros dos tratamentos de arroz e aveia preta que não diferiram entre si. Quanto ao consumo de carboidratos não estruturais (CCNE), observa-se maior consumo nos cordeiros dos tratamentos do grão de milho e da aveia preta, o que pode ser explicado, em parte, pela maior concentração na dieta e pelo maior consumo de matéria seca verificado.

Em relação aos resultados apresentados na Tabela 3, verifica-se que o peso vivo inicial (PVI), o peso vivo de fazenda (PVFAZ) e o peso vivo ao abate com jejum (PVA) foram semelhantes entre os tratamentos, confirmando assim a homogeneidade do lote de animais usados no experimento, o que era uma proposta do trabalho. Já a quebra ao jejum (QJ), em $\mathrm{kg}$ e em $\% \mathrm{PV}$, foi superior no tratamento do grão de milho quando comparado ao tratamento do arroz com casca, o que pode ser explicado pelo menor teor de FDN e maior de CNE, o que leva a uma maior taxa de passagem e de desaparecimento de conteúdo gastrintestinal durante o período de jejum pré-abate dos animais. 
Tabela 2. Valores médios para os consumos de matéria seca (CMS), matéria orgânica (CMO), proteína bruta (CPB), extrato etéreo (CEE), fibra insolúvel em detergente neutro (CFDN), fibra insolúvel em detergente ácido (CFDA), carboidratos totais (CCHO), carboidratos não estruturais (CCNE) e de nutrientes digestíveis totais (CNDT), de acordo com os tratamentos

\begin{tabular}{|c|c|c|c|c|c|}
\hline \multirow[b]{2}{*}{ Parâmetros } & \multicolumn{4}{|c|}{ Tratamentos } & \multirow[b]{2}{*}{ Média } \\
\hline & Milho & Aveia branca & Arroz & Aveia preta & \\
\hline \multicolumn{6}{|c|}{$\mathrm{kg} / \mathrm{dia}$} \\
\hline CMS & $0,885 a$ & $0,667 \mathrm{bc}$ & $0,600 \mathrm{c}$ & $0,730 \mathrm{~b}$ & 0,728 \\
\hline $\mathrm{CMO}$ & $0,841 \mathrm{a}$ & $0,631 b c$ & $0,548 \mathrm{c}$ & $0,693 b$ & 0,687 \\
\hline CPB & $0,164 \mathrm{a}$ & $0,131 b$ & $0,124 b$ & $0,133 b$ & 0,139 \\
\hline CEE & $0,020 \mathrm{a}$ & $0,017 \mathrm{a}$ & $0,007 \mathrm{~b}$ & $0,012 b$ & 0,015 \\
\hline CFDN & $0,131 \mathrm{c}$ & $0,169 \mathrm{a}$ & $0,133 b c$ & $0,160 \mathrm{ab}$ & 0,149 \\
\hline CFDA & $0,047 b$ & $0,087 \mathrm{a}$ & $0,089 \mathrm{a}$ & $0,086 \mathrm{a}$ & 0,076 \\
\hline $\mathrm{CCHO}$ & $0,652 \mathrm{a}$ & $0,483 b c$ & $0,418 \mathrm{c}$ & $0,548 b$ & 0,532 \\
\hline CCNE & $0,411 \mathrm{a}$ & $0,308 b$ & $0,284 b$ & $0,386 a$ & 0,351 \\
\hline CNDT & $0,731 \mathrm{a}$ & $0,508 \mathrm{~b}$ & $0,398 \mathrm{c}$ & $0,535 \mathrm{~b}$ & 0,553 \\
\hline \multicolumn{6}{|c|}{$\% \mathrm{PV}$} \\
\hline $\mathrm{CMS}$ & $3,34 a$ & $2,55 \mathrm{bc}$ & $2,25 \mathrm{c}$ & $2,74 \mathrm{~b}$ & 2,75 \\
\hline $\mathrm{CMO}$ & $3,18 \mathrm{a}$ & $2,41 b c$ & $2,05 \mathrm{c}$ & $2,60 \mathrm{~b}$ & 2,59 \\
\hline CPB & $0,62 \mathrm{a}$ & $0,50 \mathrm{~b}$ & $0,46 b$ & $0,50 \mathrm{~b}$ & 0,52 \\
\hline CEE & $0,08 \mathrm{a}$ & $0,07 \mathrm{a}$ & $0,03 b$ & $0,04 b$ & 0,06 \\
\hline CFDN & $0,50 \mathrm{c}$ & $0,64 a$ & $0,50 \mathrm{bc}$ & $0,60 \mathrm{ab}$ & 0,56 \\
\hline CFDA & $0,18 \mathrm{~b}$ & $0,33 \mathrm{a}$ & $0,34 \mathrm{a}$ & $0,32 \mathrm{a}$ & 0,29 \\
\hline $\mathrm{CCHO}$ & $2,47 \mathrm{a}$ & $1,85 b c$ & $1,56 \mathrm{c}$ & $2,06 \mathrm{~b}$ & 2,01 \\
\hline CCNE & $1,56 \mathrm{a}$ & $1,18 b$ & $1,06 b$ & $1,45 \mathrm{a}$ & 1,32 \\
\hline CNDT & $2,76 \mathrm{a}$ & $1,94 \mathrm{~b}$ & $1,49 \mathrm{c}$ & $2,01 \mathrm{~b}$ & 2,09 \\
\hline \multicolumn{6}{|c|}{$\mathrm{g} / \mathrm{kg} \mathrm{PV} 0,75$} \\
\hline $\mathrm{CMS}$ & $75,68 \mathrm{a}$ & $57,49 \mathrm{bc}$ & $51,00 \mathrm{c}$ & $62,09 \mathrm{~b}$ & 62,28 \\
\hline $\mathrm{CMO}$ & $71,96 \mathrm{a}$ & $54,42 \mathrm{bc}$ & $46,60 \mathrm{c}$ & $58,98 \mathrm{~b}$ & 58,74 \\
\hline $\mathrm{CPB}$ & $14,02 \mathrm{a}$ & $11,28 \mathrm{~b}$ & $10,50 \mathrm{~b}$ & $11,32 \mathrm{~b}$ & 11,88 \\
\hline CEE & $1,72 \mathrm{a}$ & $1,48 \mathrm{a}$ & $0,62 \mathrm{~b}$ & $1,01 \mathrm{~b}$ & 1,26 \\
\hline CFDN & $11,24 b$ & $14,54 \mathrm{a}$ & $11,28 \mathrm{~b}$ & $13,63 a$ & 12,74 \\
\hline CFDA & $4,06 \mathrm{~b}$ & $7,50 \mathrm{a}$ & $7,60 \mathrm{a}$ & $7,36 a$ & 6,54 \\
\hline $\mathrm{CCHO}$ & $55,80 \mathrm{a}$ & $41,67 b c$ & $35,47 \mathrm{c}$ & $46,65 \mathrm{~b}$ & 45,49 \\
\hline CCNE & $35,17 \mathrm{a}$ & $26,59 b$ & $24,13 b$ & $32,86 a$ & 29,96 \\
\hline CNDT & $62,54 \mathrm{a}$ & $43,78 b$ & $33,82 \mathrm{c}$ & $45,55 \mathrm{~b}$ & 47,32 \\
\hline
\end{tabular}

Médias na mesma linha, seguidas de letras distintas, diferem entre si pelo teste Tukey, no nível de $5 \%$ de significância.

Tabela 3. Valores médios para peso vivo inicial (PVI), peso vivo de fazenda (PVFAZ), peso vivo ao abate com jejum (PVA), quebra ao jejum (QJ), ganho de peso médio diário (GMD), conversão alimentar (CA), número de dias para o abate (DIAS), conformação (CONF) e escore de condição corporal (ECC), de acordo com os tratamentos

\begin{tabular}{|c|c|c|c|c|c|}
\hline \multirow[b]{2}{*}{ Parâmetros } & \multicolumn{4}{|c|}{ Tratamentos } & \multirow[b]{2}{*}{ Média } \\
\hline & Milho & Aveia branca & Arroz & Aveia preta & \\
\hline PVI (kg) & 20,54 & 19,65 & 20,93 & 21,40 & 20,58 \\
\hline PVFAZ (kg) & 34,02 & 33,43 & 32,80 & 32,82 & 33,31 \\
\hline PVA $(\mathrm{kg})$ & 31,88 & 31,59 & 31,46 & 31,37 & 31,59 \\
\hline QJ (kg) & $2,14 \mathrm{a}$ & $1,84 \mathrm{ab}$ & $1,34 b$ & $1,45 \mathrm{ab}$ & 1,72 \\
\hline QJ $(\%)$ & $6,29 a$ & $5,49 \mathrm{ab}$ & $4,04 \mathrm{~b}$ & $4,40 \mathrm{ab}$ & 5,15 \\
\hline GMD (kg/dia) & $0,306 a$ & $0,187 b c$ & $0,138 \mathrm{c}$ & $0,221 b$ & 0,218 \\
\hline $\mathrm{CA}$ & $3,07 \mathrm{~b}$ & $4,75 \mathrm{ab}$ & $6,07 \mathrm{a}$ & $3,55 b$ & 4,26 \\
\hline DIAS & $42,12 \mathrm{c}$ & $71,87 \mathrm{ab}$ & $85,33 \mathrm{a}$ & $50,00 \mathrm{bc}$ & 61,17 \\
\hline CONF (1-5) & 3,31 & 3,22 & 3,10 & 3,21 & 3,22 \\
\hline $\operatorname{ECC}(1-5)$ & $3,50 \mathrm{a}$ & $2,97 \mathrm{~b}$ & $2,90 \mathrm{~b}$ & $2,94 \mathrm{~b}$ & 3,10 \\
\hline
\end{tabular}

Médias na mesma linha, seguidas de letras distintas, diferem entre si pelo teste Tukey, no nível de 5\% de significância. 
Analisando-se o ganho de peso médio diário (GMD), observa-se que os animais do tratamento à base de grão de milho apresentaram um maior ganho de peso, diferindo significativamente $(\mathrm{P}<0,05)$ daqueles dos demais tratamentos, o que pode ser explicado pelo maior consumo diário de energia e de proteína bruta (Tab. 2). Resultado semelhante foi obtido por Borges et al. (2011) com uso de dietas de alto grão na terminação em confinamento de cordeiros e verificaram um valor médio 309 gramas por dia.

O menor ganho de peso foi obtido para os cordeiros do tratamento de arroz com casca, o que pode ser explicado pela diminuição da digestibilidade da dieta devido à alta presença de lignina e sílica na casca do arroz. Além disso, as características físicas abrasivas do grão de arroz com casca podem levar à redução do consumo de matéria seca e de nutrientes, afetando negativamente o ganho de peso dos animais.

O ganho de peso diário influenciou diretamente no número de dias que os cordeiros levaram para atingir o peso de abate pré-estabelecido em $32 \mathrm{~kg}$ de peso vivo, em que aqueles do tratamento com o uso de arroz com casca foram os que levaram mais tempo para serem abatidos, podendo ser considerado um aspecto negativo do sistema de confinamento.

Em relação à conversão alimentar (CA), observase que os piores valores foram obtidos para os cordeiros do tratamento que utilizou arroz com casca quando comparado com os cordeiros do tratamento do grão de milho e da aveia preta, sendo essa uma consequência do menor ganho de peso verificado nos animais desse tratamento. Deve-se destacar o valor obtido para CA nos cordeiros do tratamento à base de grão de milho, que foi de 3,07:1, o que confirma a grande eficiência dos animais submetidos a esse tratamento. Resultado semelhante foi obtido por Cardoso et al. (2006), os quais testaram diferentes níveis de fibra insolúvel em detergente neutro na terminação de cordeiros cruza Ile de France x Texel em confinamento e observaram, para o nível de $25 \%$ de FDN, um valor médio de $3,04: 1$

Para os valores de conformação (CONF), não se observou diferença significativa entre os tratamentos, fato justificado pela homogeneidade do lote de cordeiros utilizados no experimento.
Já ao se analisar os valores relacionados ao escore de condição corporal (ECC), destaca-se o tratamento do grão de milho, que diferiu dos demais tratamentos proporcionando maior grau de acabamento destes animais. $\mathrm{O}$ valor para $\mathrm{o}$ ECC dos cordeiros do tratamento do grão de milho, que foi de 3,5, em uma escala de 1 a 5 (1 $=$ muito magro e $5=$ obeso), está de acordo com as exigências de alguns frigoríficos que preconizam esse ECC como sendo o adequado para padronização do grau de acabamento de cordeiros destinados ao abate. Deve-se enfatizar que o adequado ECC proporciona uma gordura de cobertura que atua positivamente, protegendo a carcaça da desidratação durante o resfriamento, evitando o escurecimento da parte externa dos músculos, além de não prejudicar a qualidade da carne (Osório et al., 1998).

Ao se analisarem os valores apresentados na Tabela 4, observa-se que o custo da dieta, em reais por $\mathrm{kg}$ da matéria natural (CKGMN), foi significativamente diferente entre os tratamentos, em que o tratamento do arroz com casca apresentou o valor mais elevado por $\mathrm{kg}$ da dieta. Isso ocorreu porque o arroz foi o grão com maior custo no momento da compra. Além disso, devido ao seu baixo teor proteico, foi $o$ tratamento com maior necessidade de uso de farelo de soja para manter a dieta isoproteica em relação aos demais tratamentos e, dessa forma, elevando o custo da dieta total. $\mathrm{Na}$ sequência observa-se que o tratamento da aveia preta apresentou o segundo maior custo, sendo seguido pelo tratamento aveia branca e, com menor custo observado, foi a dieta à base de grão de milho. Esses custos seguiram essa ordem porque os maiores determinantes do custo total foram os valores de compra do grão utilizado.

$O$ custo da dieta por dia (CDD) foi significativamente superior no tratamento milho, mas não diferindo do tratamento de aveia preta pelo fato de serem os tratamentos com maior consumo de alimento por dia. O menor custo por dia foi observado no tratamento de aveia branca, pois, além de não ser o grão com maior custo, apresentou um baixo consumo, assim determinando esse menor custo diário da alimentação. Porém, quando se avalia o custo total da dieta (CTD) usada durante todo o período de confinamento, observa-se que o maior custo foi obtido para o tratamento do arroz com casca, o que é explicado pelo maior número de 
dias dos cordeiros desse tratamento necessários para atingir o peso de abate pré-estabelecido e, consequentemente, uma maior quantidade total de alimento ofertada aos animais. Nesse sentido, pode-se inferir que o ganho de peso e o número de dias necessários para que o cordeiro atinja o peso de abate em sistema de confinamento são importantes variáveis para viabilidade econômica do sistema.

Quando se compara o lucro total que o animal deixou no período de confinamento (LPVC), observa-se que os tratamentos milho e aveia branca foram os que proporcionaram melhor resultado econômico. Já quando se avalia o lucro por dia no período de confinamento (LPD), observa-se que os cordeiros do tratamento à base de grão de milho foram aqueles que apresentaram o melhor resultado econômico, com um lucro diário de R\$ 0,69/cordeiro/dia, sendo essa uma consequência do maior ganho de peso por dia e do menor custo praticado por sua dieta. Por outro lado, os cordeiros do tratamento com arroz com casca proporcionaram um prejuízo de R\$ 0,0013/cordeiro/dia. Portanto, para que a terminação de cordeiros em confinamento seja viável do ponto de vista econômico, deve-se trabalhar com dietas que proporcionem um desempenho satisfatório dos animais e que proporcionem uma redução do período de confinamento para que o custo total da dieta não torne inviável economicamente a utilização desse sistema.

Tabela 4. Valores médios para peso vivo inicial (PVI), peso vivo de fazenda (PVFAZ), ganho de peso no período de confinamento (GPC), oferecido de matéria natural por dia (OFMNDIA), número de dias para o abate (DIAS), oferecido total da dieta (OFTD), custo por $\mathrm{kg}$ da matéria natural (CKGMN), custo da dieta por dia (CDD), custo total da dieta (CTD), receita na venda do peso vivo (REPV), lucro do peso vivo ganho no confinamento (LPVC), lucro por kg de ganho no confinamento (LKGC), lucro por dia no período de confinamento (LPD), de acordo com os tratamentos

\begin{tabular}{|c|c|c|c|c|c|}
\hline \multirow[b]{2}{*}{ Parâmetros } & \multicolumn{4}{|c|}{ Tratamentos } & \multirow[b]{2}{*}{ Média } \\
\hline & Milho & $\begin{array}{l}\text { Aveia } \\
\text { branca }\end{array}$ & Arroz & Aveia preta & \\
\hline PVI (kg) & 20,54 & 19,65 & 20,93 & 21,40 & 20,58 \\
\hline PVFAZ $(\mathrm{kg})$ & 34,02 & 33,43 & 32,80 & 32,82 & 33,31 \\
\hline GPC $(\mathrm{kg})$ & 13,48 & 13,79 & 11,88 & 11,40 & 12,73 \\
\hline OFMNDIA (kg/dia) & $1,16 a$ & $0,88 \mathrm{bc}$ & $0,82 \mathrm{c}$ & $0,97 b$ & 0,97 \\
\hline DIAS & $42 b$ & $72 \mathrm{a}$ & $85 a$ & $50 \mathrm{~b}$ & 61 \\
\hline OFTD $(k g)$ & $48,82 b$ & $61,55 \mathrm{ab}$ & $69,20 \mathrm{a}$ & $48,97 \mathrm{~b}$ & 56,58 \\
\hline CKGMN (R\$/kg) & $0,57 \mathrm{~d}$ & $0,59 \mathrm{c}$ & $0,72 \mathrm{a}$ & $0,66 \mathrm{~b}$ & 0,63 \\
\hline $\mathrm{CDD}(\mathrm{R} \$ / \mathrm{dia})$ & $0,66 \mathrm{a}$ & $0,52 \mathrm{c}$ & $0,59 b$ & $0,64 a b$ & 0,60 \\
\hline CTD (R\$) & $27,92 b$ & $36,24 b$ & $49,94 \mathrm{a}$ & $32,47 b$ & 35,87 \\
\hline REPV (R\$) & 56,62 & 57,87 & 49,83 & 47,96 & 53,47 \\
\hline LPVC (R\$) & $28,70 \mathrm{a}$ & $21,62 \mathrm{ab}$ & $-0,11 c$ & $15,50 \mathrm{~b}$ & 17,60 \\
\hline LKGC (R\$/kg) & $2,13 \mathrm{a}$ & $1,59 \mathrm{ab}$ & $-0,009 c$ & $1,37 \mathrm{~b}$ & 1,34 \\
\hline LPD $(\mathrm{R} \$ / \mathrm{dia})$ & $0,69 \mathrm{a}$ & $0,33 b$ & $-0,0013 c$ & $0,32 \mathrm{~b}$ & 0,37 \\
\hline
\end{tabular}

Médias na mesma linha, seguidas de letras distintas, diferem entre si pelo teste Tukey, no nível de 5\% de significância.

\section{CONCLUSÕES}

O uso de dietas de alto grão de milho, aveia branca, aveia preta ou arroz com casca para terminação de cordeiros em sistema de confinamento é uma alternativa viável do ponto de vista produtivo. Porém, o uso de grão de milho proporciona melhores resultados produtivos e econômicos quando comparado com o uso de aveia branca, aveia preta ou arroz com casca.

\section{REFERÊNCIAS}

BORGES, C.A.A.; RIBEIRO, E.L.A.; MIZUBUTI, I.Y. et al. Substituição de milho grão inteiro por aveia preta grão no desempenho de cordeiros confinados recebendo dietas com alto grão. Sem. Cienc. Agr., v.32, supl.1, p.20112020, 2011.

BUTTERFIELD, R.M. New concepts of sheep growth. Sydney: University of Sydney, 1988. $168 \mathrm{p}$. 


\section{Bernardes et al.}

CARDOSO, A.R.; PIRES, C.C.; CARVALHO, S. et al. Consumo de nutrientes e desempenho de cordeiros alimentados com dietas que contêm diferentes níveis de fibra em detergente neutro. Cienc. Rural, v.36, p.215-221, 2006.

CARVALHO, S.; BROCHIER, M.A.; PIVATO, J. et al. Desempenho e avaliação econômica da alimentação de cordeiros confinados com dietas contendo diferentes relações volumoso:concentrado. Cienc. Rural, v.37, p.1411-1417, 2007.

CARVALHO, S.; PIRES, C.C.; PERES, J.R. et al. Desempenho de cordeiros machos inteiros, machos castrados e fêmeas, alimentados em confinamento. Cienc. Rural, v.29, p.129-133, 1999.

COTAÇÃO de preços de grãos. 2014. Disponível em: <http://www.agrolink.com.br/ cotacoes/graos/aveia>. Acessado em: 10 mar. 2014.

KOZLOSKI, G.V.; PEROTONI, J.; CIOCCA, M.L.S. et al. Potencial nutricional assessment of dwarf elephant Grass (Pennisetum purpureum schum. Mott) by chemical composition, digestion and net portal flux of oxygen in catle. Anim. Feed Sci. Technol., v.104, p.29-40, 2003.

MERTENS, D.R. Análise da fibra e sua utilização na avaliação de alimentos e formulação de rações. In: SIMPÓSIO INTERNACIONAL DE RUMINANTES, 1992, Lavras. Anais... Lavras: Sociedade Brasileira de Zootecnia, 1992. p.188-219.

NUTRIENT requirements of small ruminants: sheep, goats, cervids, and new world camelids. New York: National Academy Press, 2007. $384 p$.
OFFICIAL methods of analysis. 16 ed. Virginia: AOAC International, 1995. 1094p.

OSÓRIO, J.C.S; OSÓRIO, M.T.M.; JARDIM, P.O. et al. Métodos para avaliação da produção de carne ovina, in vivo, na carcaça e na carne. Pelotas: UFRS, 1998. 107p.

PANIAGO, R. Dietas de alto grão $\mathrm{x}$ alto volumoso. 2014. Disponível em: $<$ http://www.boviplan.com.br/boviplan.asp?idS= 2\&idS2=12\&idT=90>. Acessado em: $10 \mathrm{fev}$. 2014.

SENGER, C.C.D.; KOZLOSKI, G.V.; SANCHES, L.M.B. et al. Evaluation of autoclave procedures for fiber analysis in forage and concentrate feedstuffs. Anim. Feed Sci. Technol., v.146, p.169-174, 2008.

SILVA, D.J.; QUEIROZ, A.C. Análise de alimentos: métodos químicos e biológicos. 2.ed.Viçosa: UFV, 2002, 175p.

SNIFFEN, C.J.; O'CONNOR, J.D.; VAN SOEST, P.T. et al. A net carbohydrate and protein system for evaluating cattle diets; II. Carbohydrate and protein availability. J. Anim. Sci., v.70, p.3562-3577, 1992.

STATISTICAL analysis system - SAS/STAT. Version 9.0. Cary: SAS Institute, 2004.

VECHIATO, T.A.F.; ORTOLANI, E.L. Dieta de alto grão VS urolitíase em pequenos ruminantes. 2008. Disponível em: $<$ http://www.farmpoint.com.br/radares-tecnicos/ sanidade/dieta-de-alto-grao-vs-urolitiase-empequenos-ruminantes-49582n.aspx $>$. Acessado em: 12 jan. 2014. 